\title{
Determination of Accuracy Level for Energy Modelling Tools in Office Buildings in Jos, Nigeria
}

\author{
Ademola Olatunji Jimoh Ochapa Onazi \\ Faculty of Environmental Sciences, Dept. of Architecture University of Jos, Jos City, Nigeria
}

\begin{abstract}
The research undertook a comparative analysis of results obtained from both Real-time energy consumption measurements and computerized energy use simulations. The purpose was to find the level of accuracy/reliability of data obtainable (Test-Out-Theory) thus leading to a greater efficiency of energy planning decision support tools in the context of their utilization in the sub Saharan regions. eQUEST 3-65 software was used for the purpose of simulation of energy consumption. A $72 \%$ cumulative accuracy level was obtained for randomly selected buildings under study. The research therefore recommends that energy performance simulation tools are veritable and viable devices for estimation of potential energy consumption of building at pre and post design stages.
\end{abstract}

Keywords: Sustainability, Energy Performance, Energy Planning, Energy Modelling, Computerized Energy Simulation, eQUEST 3-65 software.

DOI: $10.7176 / \mathrm{CER} / 11-1-07$

\subsection{INTRODUCTION}

Energy modelling is the disaggregation of the total energy uses by a building into components of the energy such as costs of fan motor operation, space heating, space cooling, lighting and equipment (i.e building and process load). These data are often inputted vie scripted programs into the computer for analysis and simulation. This has been, over the year, the bases for energy performance assessment.

Historically, the United State Department of Energy (DOE) proposed the first Building Energy Performance Standards (BEPS) in 1979. This standard was called US DOE 1979. This set maximum level of quality accepted as norm in terms of energy performance for both residential and commercial buildings. A key feature of both this development and the proposed standards was the innovative use of building performance simulation. Here, unique properties of typical buildings within United States were articulated and performance simulation models were designed for more than 20 buildings based on their types. Simulations were then performed and target levels established. The data obtained by running these simulations thus became a base for designers to establish the efficiency of their building with respect to energy use. Due to its advance features, as at then, it was difficult for a user to embrace it readily. However, recent development has led to more intuitive and user friendly simulation techniques.

In Europe however, the European Union (EU) came up with a policy on the Energy Performance of Buildings (CEC 2001), this made it mandatory for member states to create and deploy calculation methods for rating energy performance for buildings larger than $1,000 \mathrm{~m} 2$. This rating has a scale of $\mathrm{A}$ to $\mathrm{H}$, where $\mathrm{A}$ is the lowest-energy and $\mathrm{H}$ the highest-energy buildings. This has led to an increase in the number of building performance modeling executed in Europe than was previously obtainable.

In Nigeria, the Government came up with the Building Energy Efficiency Guideline (BEEG), this was developed in consonance with the Nigerian Energy Support Programme (NESP). It intends to provide useful information for professionals in the country's building sector on appropriate considerations in the designing of energy efficient buildings. The aspects of the building, which the BEEG aims to impact include: the architectural design; materials used in construction; HVAC used in the building; regional hazards common in Nigeria; and tools for analyzing energy efficiency. This, so far, is a guideline. It is hoped that it will eventually become a holistic regulatory framework for energy efficiency in buildings in Nigeria.

Researches on energy simulation in Nigeria are rare. An exception is Mu'azu (2011), this research, conducted in Abuja-Nigeria, falls within the ambit of a comprehensive general audit and it carried out energy audit of government buildings in Abuja. Using SPSS based correlation analyses; it was able to garner information useful to the architects in understanding the relationship between their design decisions and energy use implications in the context of a developing country. Also, simulated prototypical office building model were executed using the Integrated Environmental Solution Virtual Environment software (IES VE) to examine the impact and relative importance of design variables on internal comfort and associated cooling load.

In the context of building performance simulation software, this has been available for more than 40 years (Clarke 2003). This has evolved from a strictly text-based, scripted input and output to a more user-friendly multiple interfaces for different uses and users. Modern simulation models are characterized by flexibility and accuracy, thereby improving the user-friendliness of these softwares. It is no longer necessary to under study the underlying scripted programs. This has dramatically increased its acceptability amongst designers and policy 
makers alike. This research is a further study into its applicability in sub Saharan region especially in the context of post and pre-design stages.

Techniques for energy performance assessment of buildings often involves Computerized Energy Simulation Model or on-site direct measurements or a combination of both. This research undertook a comparative analysis of results obtained from both types of energy assessment techniques (Building Energy Modeling and Computerized Energy Use Simulation). The purpose was to find the level of accuracy/reliability of data obtainable (Test-Out-Theory) thus leading to a greater efficiency of energy planning decision support tools in the context of their utilization in the sub Saharan region. This is to assist in determining possible energy savings using energy modeling software. This data can also be used in the development of building regulations or appliance energy efficiency ratings.

eQUEST 3-65 software was used for the purpose of simulation of energy consumption. This is an extensive tool that can be used for detailed analysis during the design development and design optimization or assessment phase. This therefore becomes the tool of choice for the purpose of this research.

The data thus obtained from this simulation was correlated with that obtained by real-time measurement of energy consumption of the building under research. The result of this research will key into the proposed Building Energy Efficiency Guideline (BEEG) for buildings in Nigeria (See Fig 1 and 2).

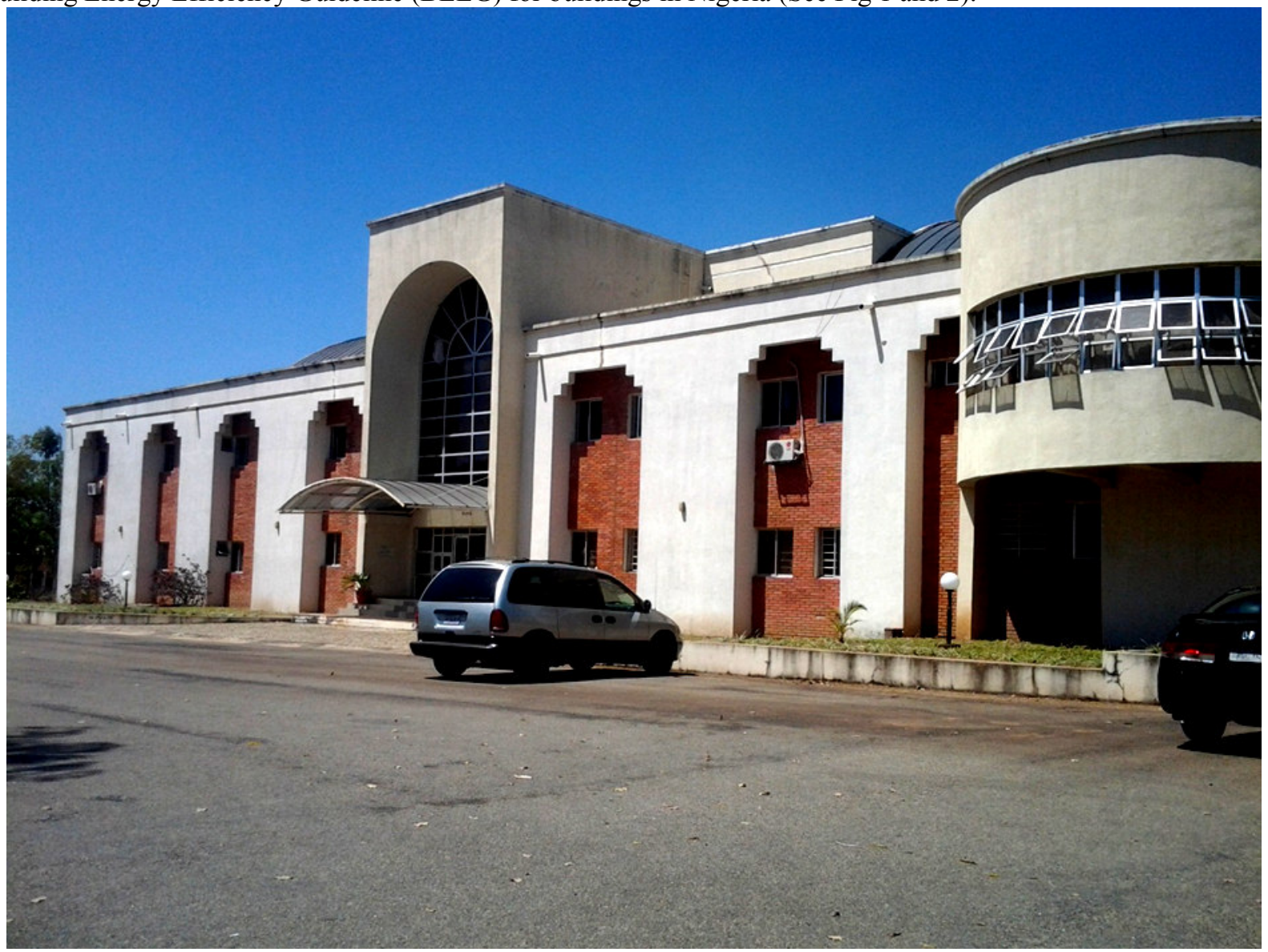

Fig 1: Typical Administrative Building Studied (Building ID: NIPSS ADMIN). 


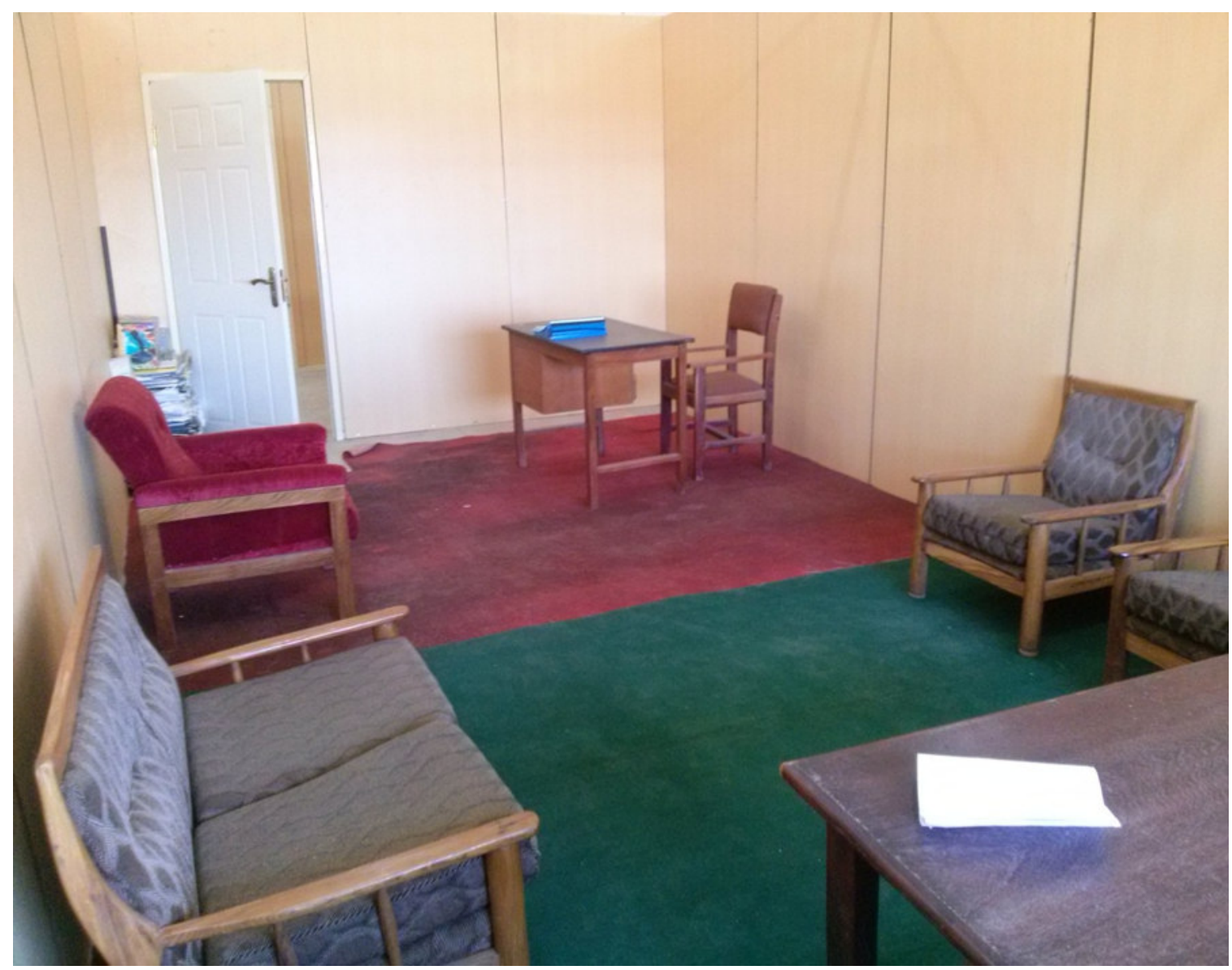

Fig 2: Typical Interior of Office Studied.

\subsection{AIM OF THE STUDY}

To determining the level of accuracy and thus appropriateness of energy modelling softwares in building analysis. This is to certify these tools as efficient devices in pre and post design energy use analysis.

\subsection{METHODOLOGY OF STUDY}

The study was carried out in the month of May 2015 in Jos, Nigeria. The location had an altitude above sealevel of 1286 meters. The GPS location is given in Table 1. All offices under study were selected randomly, east-facing and naturally ventilated (NV). The period of study was between $8.00 \mathrm{hrs}$ and $15.00 \mathrm{hrs}$ week days.

eQUEST 3-65 software was used for the purpose of simulation of energy consumption. This is an extensive tool that can be used for detailed analysis during the design development and design optimization or assessment phase. This therefore becomes the tool of choice for the purpose of this research.

In a building assessment for energy performance, we have an interplay of Building Energy Modeling (energy audit) and Computerized Energy Use Simulation. The purpose is to find the level of accuracy/reliability of data obtainable in both cases for same building and to determining the energy characteristics of building envelope and other design characteristics.

A comprehensive building material types used for the purposes of enveloping was also itemized for a given administrative building. This was achieved by inputting data collected such as buildings floor plans, sections, elevation, building orientation, rate of occupancy, schedule of use etc (See Table 1).

All these were entered into the energy simulation programs (eQUEST 3-65) and the energy simulation executed (Computerized Energy Use Simulation).

Finally, these simulated models are calibrated against the actual data obtained from the disaggregated survey or disaggregated utility bills (real-time energy use). This enabled the establishment of the degree of accuracy of energy modeling tools.

\subsection{Real-Time Energy Use}

Utility bills are often aggregated data and therefore lack component data to grant understanding as to possible areas of waste or savings or accuracy of billing systems. However, through real-time energy metering, an energy performance specialist can understand past, immediate and projected energy usage and work towards optimizing 
its process. This is done through the process of Reporting, Monitoring and Engagement. The reporting aspect includes the authentication of energy use data. Monitoring included trend analysis, while engagement involved real time response to area of waste or saving, this can be either automated or manual.

Energy metering or real-time energy monitoring, on the other hand, is the method of measuring the actual amount of electric energy consumed by a residence, an office building, or an electrically power-driven device in real time. This enables quick and handy feedback on electrical or other energy use. Depending on device used, information available might include cost of energy used, and estimates of greenhouse gas emissions and areas of possible savings.

\subsection{Wireless Electricity Monitor}

An E2 Wireless Electricity monitor was used to evaluate, in real time, electricity consumption of the building under research. This is attached by a CT Sensor to the live cable of the service panel. The CT Sensors relays the amount of current being drawn to the transmitter and ultimately to the monitor. The monitor records time, date, energy used and carbon emission as a result of energy consumption. It has a voltage range of 110 volts to 400 volts and a measuring current of 50mA to 200A (See Fig 3 and 4).

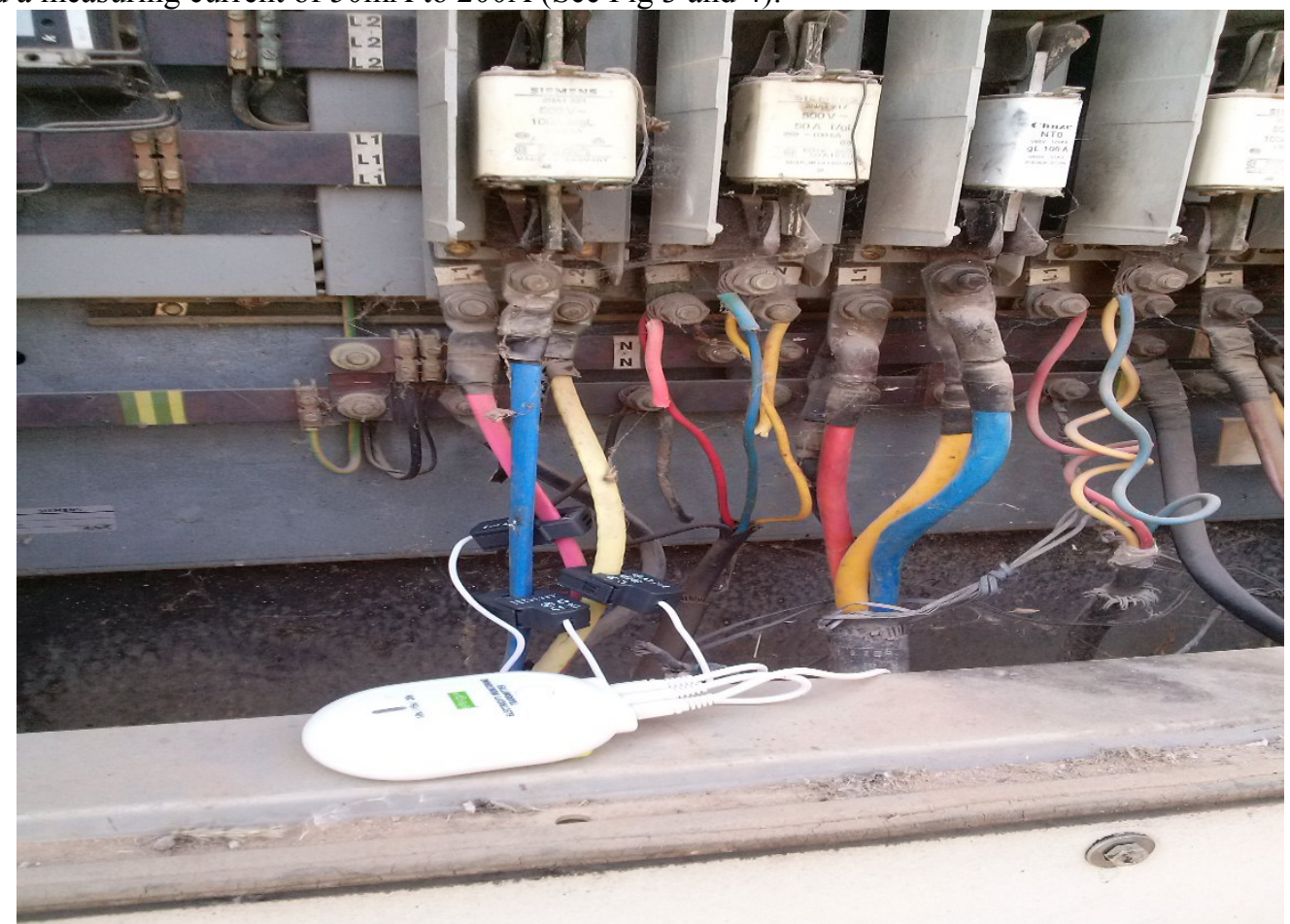

Fig 3: Wireless Energy Monitoring Device Installed at Point of Supply in Office Building.

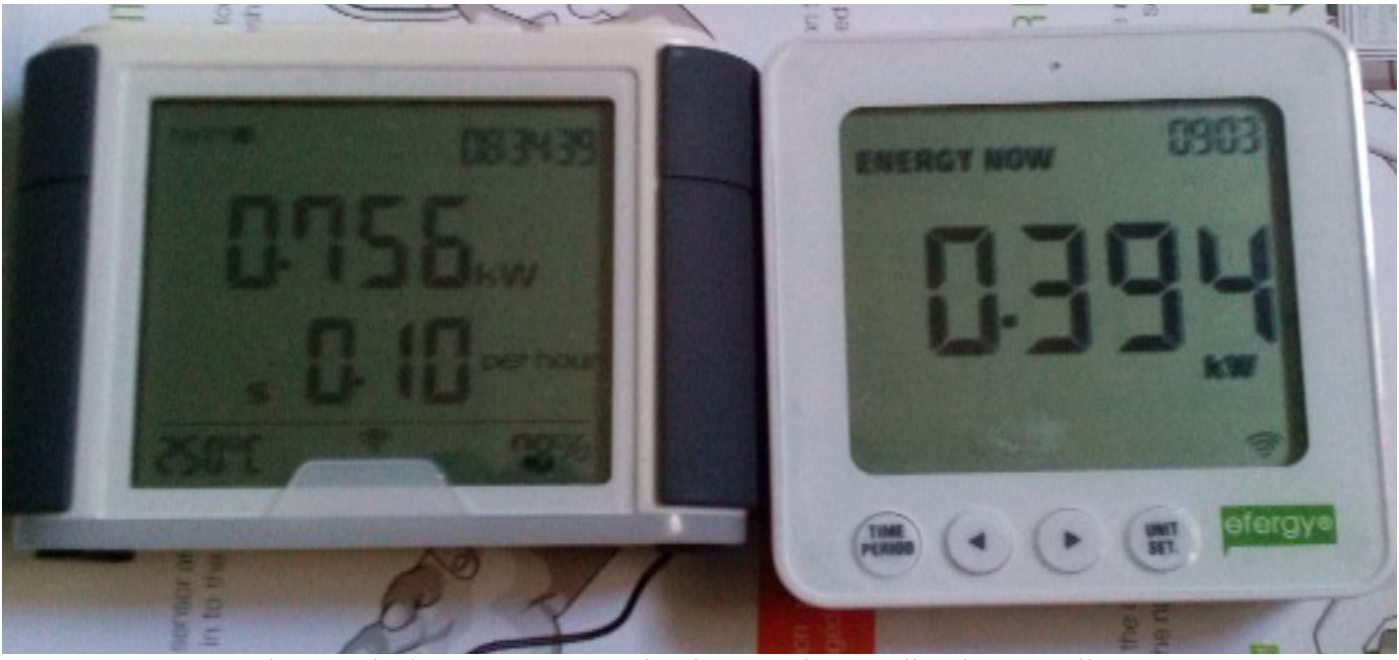

Fig 4: Wireless Energy Monitoring Devices Indicating Readings. 


\subsection{Global Positioning System}

A Cobra GPS 100 global Positioning System receiver was used to obtained global location of building of interest (See Table 1). This device provided accurate positioning to within 3 meters, if held in any position open to the sky. It offers information as to current positioning, altitude above sea level, bearing and time of the day.

\subsection{Methods of Objective Data Analysis.}

For objective data from questionnaires, data presented were analyzed using simple bar graphs and percentages. This is to grant visual correlation to relationships between the variables under study. This enhances understanding of subsequent objectives inputs and inferences.

\subsection{FIELDWORK}

The primary aim of performance simulation is to evaluate the energy savings possible in comparison with a proposed standard (as compared to typical building practice or existing standards). The objective data for this research was obtained from measurement instruments. The results were subject to tables and simple graphs to grant visual understanding into the subject matter. Needed physical attributes such number of floors, building shape etc were noted and inputted into the required software.

\subsection{Sample Area Characteristics}

Jos, plateau state is characterized by rocky terrain (topography) giving rises to plateaux and plains, hills and valleys. It enjoys a unique climate (temperate climate) than must of the rest of Nigeria. Jos is located in JosNorth local government area of the state. It is at an altitude of $1,217 \mathrm{~m}(3,993 \mathrm{ft})$ above sea level. The wet season starts from April - October and the dry season starts from November- march. The mean annual rainfall here is about $320 \mathrm{~mm}$ in the month of august with an average monthly temperature ranging from $21^{\circ} \mathrm{C}-25^{\circ} \mathrm{C}$. From mid-November to late January, night time temperatures drop as low as $11^{\circ} \mathrm{C}$. Daily solar radiation averages over $4300 \mathrm{wh} / \mathrm{m} 2$ per annum annually. For most periods in the year, the sun sets in at relatively low altitudes at the West and conversely rises from the East.

Data acquisition for the purposes of this energy simulation accuracy test was carried out in Jos, Nigeria. The studies were executed in three (3) different administrative buildings within Jos city, Nigeria (See Fig 1 and 2). This was conducted in Naturally Ventilated (NV) building in the month of May 2015. In obtaining objective data using instruments earlier enumerated, there was the need to conduct the instrument data session within a given season in time. This is to ensure integrity and interoperability of data collected.

Table 1: Summary of Survey Locations' Environmental Variables

\begin{tabular}{|c|c|c|c|c|c|c|c|}
\hline OFFICE ID & Lat. (N) & Long. (E) & Alt. (M) & Date & To (O) & Vo (cfm) & Rho (\%) \\
\hline UJ/ADMIN & $09^{0} 57.830$ & $08^{0} 53.630$ & 1286 & $7^{\text {th }}$ May 2015 & 32 & 672 & 49.5 \\
\hline NIPSS/ADMIN & $0^{\circ} 9^{\circ} 44.726$ & $08^{\circ} 49.084$ & 1263 & $8^{\text {th }}$ May 2015 & 33 & 655 & 43.8 \\
\hline MIN/LSTP & $0^{\circ} 54.982$ & $08^{\circ} 53.242$ & 1232 & $7^{\text {th }}$ May 2015 & 32 & 611 & 46.8 \\
\hline
\end{tabular}

\section{Where:}

Lat: Latitude $\left({ }^{\circ} \mathrm{N}\right)$

Long.: Longitude $\left({ }^{\circ} \mathrm{E}\right)$

Alt.: Altitude (m)

To (oC) Average outdoor temperature recorded at the time of survey

Vo (cfm) Average outdoor wind velocity recorded at the time of survey

RHo (\%) Average outdoor Relative Humidity recorded at the time of survey 
Table 2: Input and Output Data for Measured and Simulated Schemes.

\begin{tabular}{|c|c|c|c|}
\hline \multirow[b]{2}{*}{ MODELLING PARAMETER } & \multicolumn{3}{|c|}{ BUILDING ID } \\
\hline & UJ/ADMIN & NIPSS/ADMIN & MIN/LSTP \\
\hline SHAPE OF BUILDING & SQUARE/ATRIUM & RECTANGLE & RECTANGLE \\
\hline ENERGY ZONING PATTERN & 1 PER FLOOR & 1 PER FLOOR & 1 PER FLOOR \\
\hline FLOOR HEIGHT & 10FT & 10FT & 10FT \\
\hline NUMBER OF FLOORS & 2 & 2 & 1 \\
\hline WEATHER FILE & $\begin{array}{l}\text { WEATHER DATA } \\
\text { TAMPA FLORIDA }\end{array}$ & $\begin{array}{l}\text { WEATHER DATA } \\
\text { TAMPA FLORIDA }\end{array}$ & $\begin{array}{l}\text { WEATHER DATA } \\
\text { TAMPA FLORIDA }\end{array}$ \\
\hline HVAC EQUIPMENT & NONE & NONE & NONE \\
\hline BUILDING AREA & $1,524 \mathrm{~m}^{2}$ & $648 \mathrm{~m}^{2}$ & $273 \mathrm{~m}^{2}$ \\
\hline USAGE DETAIL & $8 \mathrm{AM}$ TO 3PM & 8AM TO 3PM & 8AM TO 3PM \\
\hline SEASON CYCLES & 2 & 2 & 2 \\
\hline SEASON PERIOD & $\begin{array}{c}01 / 03 \text { to } 30 / 09 \text { and } \\
01 / 10 \text { to } 30 / 04\end{array}$ & $\begin{array}{c}01 / 03 \text { to } 30 / 09 \text { and } \\
01 / 10 \text { to } 30 / 04\end{array}$ & $\begin{array}{c}01 / 03 \text { to } 30 / 09 \text { and } \\
01 / 10 \text { to } 30 / 04\end{array}$ \\
\hline OCCUPANCY RATE (\%) & 90 & 70 & 50 \\
\hline DAYLIGHT CONTROL & NONE & NONE & NONE \\
\hline ENERGY SIMULATED & $5.78 \mathrm{kWh}$ & $1.91 \mathrm{kWh}$ & $0.98 \mathrm{kWh}$ \\
\hline ENERGY MEASURED & $4.07 \mathrm{kWh}$ & $1.33 \mathrm{kWh}$ & $1.11 \mathrm{kWh}$ \\
\hline LEVEL OF ACCURACY & $70.4 \%$ & $69.6 \%$ & $88 \%$ \\
\hline $\begin{array}{c}\text { PERFORMANCE INDEX } \\
\left(M^{2} / \mathbf{k W h} / \text { Year }\right)\end{array}$ & 32 & 41 & 21 \\
\hline CARBON EMISSION/HOUR & $2.27 \mathrm{KgCo} 2$ & $0.74 \mathrm{KgCo} 2$ & $0.69 \mathrm{KgCo} 2$ \\
\hline CARBON EMISSION/M² & 671.4 & 875.7 & 395.7 \\
\hline
\end{tabular}

\subsection{ANALYSIS OF FINDINGS}

Appropriate weather data file of location of research in formats compactible to the software used was not available. The closest weather characteristics to that obtained in research location is Tampa Florida, USA. A weather file for this was downloaded into the software for the purposes of simulation. Central HVAC equipment was treated as not existing for the purpose of this research and so was daylight control. While real time energy measurement was executed on hourly bases (See Fig. 5). A 72\% cumulative accuracy level was obtained across board. Here, it was observed that buildings with lower floor areas obtained better level of accuracy (See Table 2 and Fig 6).

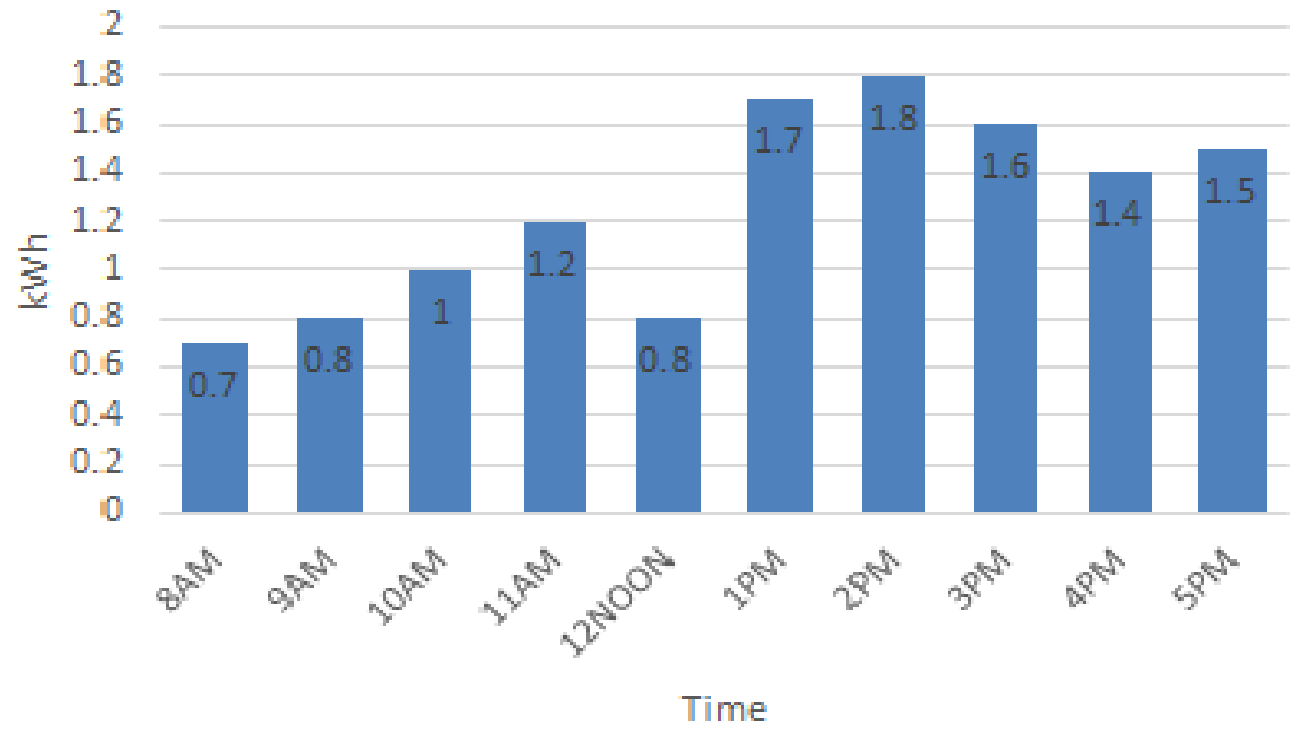

Fig 5: Typical Real Time Energy Use (Average kWh every Hour) for Building ID MIN/LSTP. 


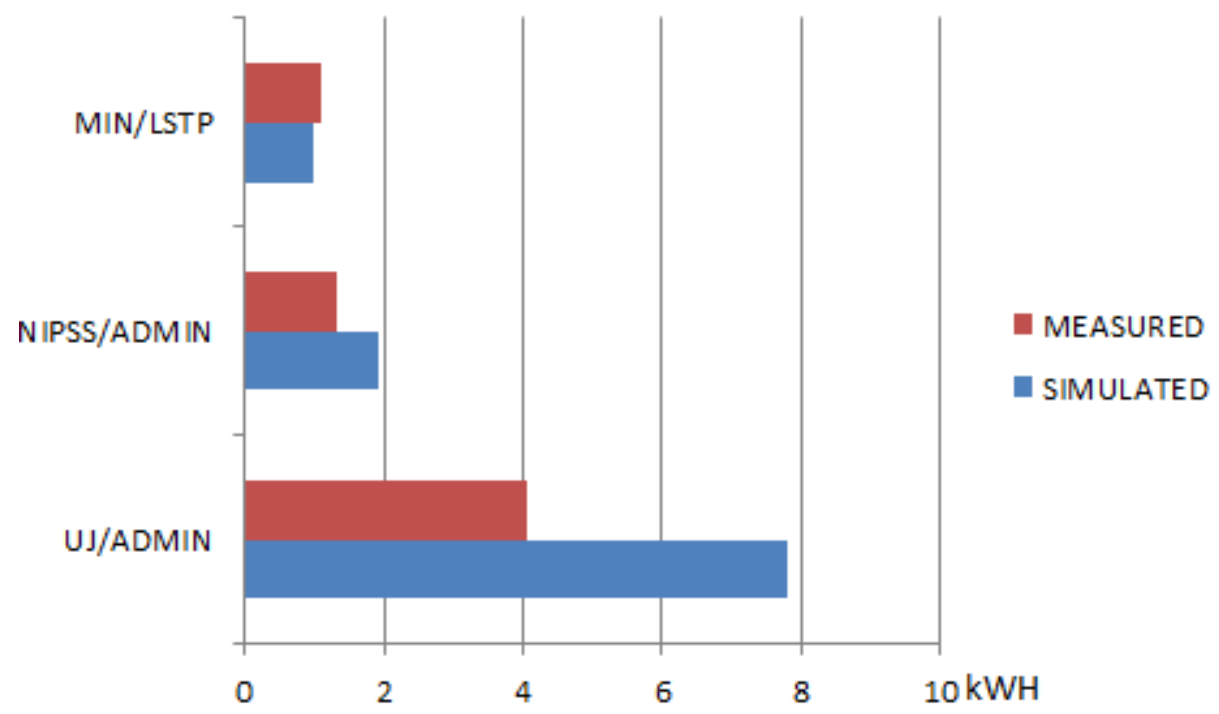

Fig 6: Graph Showing Difference Between Measured and Simulated Data

\subsection{CONCLUSION}

Energy use simulation is the virtual or computerized simulation of a building with the sole purpose of obtaining data as to energy consumption, utility bills and life cycle costs of various energy related items such as air conditioning and lights.

In a way, building simulation is a powerful tool to inform the design and decision-making process by quantitatively predicting future energy use and thus providing considerable added value to the design process. Properly used, energy simulation modelling optimizes the building design and allows the design team to prioritize investment in the solutions that will have the greatest benefit on the building's energy use.

For the purpose of this research, the software used was eQUEST 3-65. The relationship between measured energy and simulated energy use showed an average level of accuracy of $76 \%$ for this simulation tool. Also, a critical observation of data obtained by this simulation indicates that buildings with smaller floor obtained a more accurate result.

\subsection{RECOMMENDATION}

1) As to accuracy of energy performance simulation tools, the research conducted real-time measurement of energy consumption for randomly selected buildings within the accessed population of this research. A $72 \%$ cumulative accuracy level was obtained. The research therefore recommends that energy performance simulation tools are veritable and viable devices for estimation of potential energy consumption of building at design stage and in retrofitting exercises.

2) Government agencies are the most critical source of the power generating company's illiquidity is an indication of the magnitude of their demand in the energy sector (Nnaji, 2012). Energy performance assessment of government buildings will therefore be part of the solution to the energy crisis as this will serve as an incentive and a Test-Bed for energy policy formulation by government agencies (See Fig 1 and 2). Research shows that due to the factor of scale, government policies formulation as energy conservation tool, are the most effective means of tackling energy crisis. Government should play a crucial role in setting the cross-sectoral framework for energy efficiency. Government can help to stimulate investment in energy efficiency and accelerate implementation through national energy efficiency strategies hence granting security to potential investors.

By virtue of economy of scale, the federal government can offer efficiency incentive early in the development process and across the country's energy market. This can be highly leveraged for maximum effect. The federal government can also set uniform standards for all electrical appliances by establishing compulsory rating systems. This minimizes the regulatory burden of fulfilling different state-level mandates while maximizing the policy's potential impact on national energy demand (Doris, Cochran, \& Vorum 2009).

3) Climate and weather conditions differ from place to place, even within the sub-saharan region were the research was executed. There would be need for similar research to be conducted in areas with differing climatic conditions. This is to grant validity to the research focus.

4) The common challenge of using energy simulation softwares in developing regions is that the gamut of material type used in building construction in these regions are not adequately represented in these softwares. Also, most developing countries lack jurisdiction building codes which are also a required input in these 
softwares. This limits the ability of these tools to accurately predict thermal performance of buildings in subSaharan regions. Energy simulation tools with broader technical capabilities would therefore be needed for future research.

\subsection{REFERENCES}

Aydinalp, M., Ugursal, V.I., \& Fung, A.S. (2003). Modelling of residential energy consumption at the national level. International Journal of Energy. 27(5), 441-53.

Clark, J.A. (2001). Energy simulation in building design, (2 ${ }^{\text {nd }}$ ed.). London: Butterworth-Heinemann.

Clark, J. A., Johnstone, C. M., Lever, M., \& McElroy, T. (2003). Simulation support for the formulation of domestic sector upgrading properties. Netherlands: Eindhoven.

Crawley, D.B. (2008). Building performance simulation: A tool for policy making. (Ph.D dissertation). Scotland: University of Strathclyde, Glasgow.

Doris, E., Cochran, J., \& Vorum, M. (2009). Energy efficiency policy in the United States: Overview of Trends at Different Levels of Government. Washington: National Renewable Energy Laboratory: Technical Report NREL/TP-6A2-46532.

EQUEST 3-65, (2003). Retrieved from http://www.eQUEST 3-65.gov. Fanger, O.P., \& Toftum, J. (2002). Extension of the PMV model to non-air-conditioned buildings in warm climates. Energy and Buildings, 34, 533-536.

Klien, S.A., Beckman, W.A., \& Mitchel, J.W. (2004). A TRaNsient system simulation programme. User's Manual. Madison: Solar Energy Laboratory. University of Wisconsin.

Mu'azu, A. I. (2011). Energy efficiency in green design approach: A case study of government office buildings in Abuja. Portsmouth: Portsmouth School of Architecture.

Mu'azu, A. I. (2012). Promoting energy use regulations for a sustainable built environment in Nigeria. Abuja: Talos Press.

Nnaji, B. (2012). Nigeria's electrical power sector. A public lecture by Prof. Barth Nnaji. Honorable Minister for Power Organized by the Nigerian Academy of Science. May 10, Ritz Hotel, Abuja. 